NBER WORKING PAPER SERIES

\title{
THE ANATOMY OF A HOSPITAL SYSTEM MERGER: THE PATIENT DID NOT RESPOND WELL TO TREATMENT
}

\author{
Martin Gaynor \\ Adam Sacarny \\ Raffaella Sadun \\ Chad Syverson \\ Shruthi Venkatesh \\ Working Paper 29449 \\ http://www.nber.org/papers/w29449
NATIONAL BUREAU OF ECONOMIC RESEARCH
1050 Massachusetts Avenue
Cambridge, MA 02138 \\ November 2021, Revised November 2021
}

We thank Bob Gibbons, Tal Gross, Carol Propper, Melanie Wasserman and seminar participants at the MIT Sloan Organizational Economics lunch seminar for their helpful comments. We are grateful to Margaret Dalton and Darwin Yang for excellent research assistance. Our access to CMS data was supported by a pilot award from the National Institute on Aging (P01-AG005842). We thank Maurice Dalton and Mohan Ramanujan for their assistance with this data. The views expressed herein are those of the authors and do not necessarily reflect the views of the National Bureau of Economic Research.

At least one co-author has disclosed additional relationships of potential relevance for this research. Further information is available online at http://www.nber.org/papers/w29449.ack

NBER working papers are circulated for discussion and comment purposes. They have not been peer-reviewed or been subject to the review by the NBER Board of Directors that accompanies official NBER publications.

(C) 2021 by Martin Gaynor, Adam Sacarny, Raffaella Sadun, Chad Syverson, and Shruthi Venkatesh. All rights reserved. Short sections of text, not to exceed two paragraphs, may be quoted without explicit permission provided that full credit, including $(\odot)$ notice, is given to the source. 
The Anatomy of a Hospital System Merger: The Patient Did Not Respond Well to Treatment Martin Gaynor, Adam Sacarny, Raffaella Sadun, Chad Syverson, and Shruthi Venkatesh NBER Working Paper No. 29449

November 2021, Revised November 2021

JEL No. D22,I11,M12

\begin{abstract}
$\underline{\text { ABSTRACT }}$
Despite the continuing US hospital merger wave, it remains unclear how mergers change, or fail to change, hospital behavior and performance. We open the "black box" of hospital practices through a mega-merger between two for-profit chains. Benchmarking the merger's effects against the acquirer's stated aims, we show they achieved some of their goals, harmonizing electronic medical records and sending managers to target hospitals. Post-acquisition managerial processes were similar across the merged chain. However, these interventions failed to drive detectable gains in performance. Our findings demonstrate the importance of organizations for merger research in health care and the economy more generally.
\end{abstract}

\author{
Martin Gaynor \\ Heinz College \\ Carnegie Mellon University \\ 5000 Forbes Avenue \\ Pittsburgh, PA 15213-3890 \\ and NBER \\ mgaynor@cmu.edu \\ Adam Sacarny \\ Mailman School of Public Health \\ Columbia University \\ 722 West 168th Street \\ New York, NY 10032 \\ and NBER \\ ajs2102@columbia.edu \\ Raffaella Sadun \\ Harvard Business School \\ Morgan Hall 233 \\ Soldiers Field \\ Boston, MA 02163 \\ and NBER \\ rsadun@hbs.edu
}

\author{
Chad Syverson \\ University of Chicago \\ Booth School of Business \\ 5807 S. Woodlawn Ave. \\ Chicago, IL 60637 \\ and NBER \\ chad.syverson@chicagobooth.edu \\ Shruthi Venkatesh \\ Carnegie Mellon University \\ shruthiv@cmu.edu
}


Hospital consolidation through mergers and acquisitions has been a ubiquitous feature of U.S. health care sector dynamics for more than two decades, with nearly 1,600 hospital mergers occurring during 1998-2017 (Gaynor, 2020). A large economics literature has studied the effects of this trend (see Gaynor et al., 2015). Much of it has focused on measuring changes in market power and price effects (e.g. Cooper et al., 2019; Gowrisankaran et al., 2015; Tenn, 2011), though a substantial body of work has also looked at clinical outcomes (Beaulieu et al., 2020; Capps, 2005; Kessler and McClellan, 2000; Romano and Balan, 2011), and many papers examine impacts on costs (Burns et al., 2015; Schmitt, 2017; Tsai and Jha, 2014). While these studies provide critical contributions to the assessment of merger effects, the mechanisms underlying the impacts of mergers on key outcomes (or lack thereof) remain unclear.

In this paper, we pull back the curtain on the inner workings of hospital mergers by leveraging a particularly large and consequential acquisition. The setting is ideal for this "opening the black box" exercise. First, this mega-merger was important in its own right: it involved two of the largest forprofit chains in the U.S. comprising over 100 individual hospitals. ${ }^{1}$ Second, by focusing on a single merger, we can benchmark the changes we see against the claims the acquirer made, particularly those about the use of certain inputs. To that end, we observe a host of rich metrics on hospital inputs that closely track the acquirer's goals, including health IT purchases and the entry and exit of physicians and managers. Third, and unique to our study, we survey the leadership of these hospitals about management processes and strategies to see further inside the organization and how it managed the merger. Management is a key input in hospital performance (Bloom et al., 2012; McConnell et al., 2013) but is unobservable in typical producer data in the health care sector or any other industry. Finally, we observe many clinical and financial performance metrics that the existing literature on

\footnotetext{
${ }^{1}$ Our data use agreement prohibits us from revealing the names of the two chains.
} 
hospital mergers typically studies as outcomes. Our findings on these downstream outcomes tend to align with prior literature on average merger effects, suggesting that our results about mechanisms could have more general applicability.

Concisely stated, we find that improving hospital performance through mergers is difficult, as indicated by either metrics of private firm performance or social benefit. Despite having a longstanding strategy and history of growth through acquisition, the acquiring firm had difficulty improving either the financial or clinical performance of the target hospitals, even eight years after acquisition. Performance remained unchanged even though the merger led to changes in intermediate inputs that might have seemed to herald success. The acquirer was able to install many new executives in the target hospitals (often coming from the acquirer's existing hospitals) and drive adoption of a new electronic medical record (EMR) system at targets. We also see a great deal of similarity in management practices within the merged hospital network compared to other hospital chains.

Despite these organizational changes, there were no substantial improvements in targets' outcomes. Their profitability did not measurably rise. Prices rose, but so did costs, with little detectable impact on quality of care. Patients' clinical outcomes, particularly survival rates, were little changed. Indeed, the only clear change in major outcomes tied to the merger was the profitability of the acquiring firm's existing hospitals, and in a negative direction: relative to other for-profit hospitals, their post-merger profit rates fell 3 percentage points. We speculate that this decline might result from shifts in the acquirer's attention and resources away from its existing operations and toward its newly purchased hospitals, evocative of the "new toy" effect found in other sectors (Schoar, 2002).

\section{Setting}

The focal acquisition of this study occurred in 2007. At that time, the acquiring chain was the largest non-urban hospital chain in the U.S. and among the top five for-profit chains overall, whether 
measured in beds or revenues. The chain had a publicly declared strategy of growth by acquisition. It had acquired 43 hospitals in the six years prior to our focal merger; the total of that gradual expansion was of similar magnitude to the single acquisition we study. The past purchases tended to be small not-for-profit and faith-based institutions in rural areas.

The acquisition we focus on here differed from the previous mergers in two key ways. First, it involved a very large number of hospitals (49), while past acquisitions typically were singletons. Second, the target facilities differed observably from legacy facilities, including those previously acquired. The targets in this acquisition tended to have superior clinical and financial outcomes, and they were larger and more likely to be in urban areas (Table 1). The acquisition nearly doubled the size of the acquirer as measured by hospital beds.

We now review the acquirer's stated aims and the metrics we use to monitor achievement of these goals and impacts on consumers (patients). The acquirer claimed the merger would save tens of millions of dollars from overhead reductions, renegotiated purchasing contracts, and optimizing resource allocations across hospitals. We therefore track effects on hospital costs and employment. The firm cited expected performance gains from reducing unnecessary capital expenditures, which we track using investment data; opening its physician recruitment program to the newly acquired hospitals, which we measure by following physician inflows and outflows; and standardizing operations, which we assess by measuring new EMR adoption, flows of managers within the merged chain, and our direct surveys of leadership on management practices. $^{2}$

The acquiring firm forecasted these efficiencies would be realized by implementing an aggressive integration plan overseen by a dedicated and experienced team within two years of the

\footnotetext{
2 The firm also expected profits and efficiencies from selecting hospitals in growing markets and by making emergency room improvements. We do not directly test these goals but note them for completeness.
} 
acquisition. Still, the stock market reacted skeptically, and analysts noted this acquisition's departure from the firm's earlier expansion strategy (Figure A1).

We note that the firm could achieve its stated goals without having to pass the benefits on to consumers (here, patients). We therefore also assess metrics of patient and consumer impacts like price and quality of care to ascertain if the merger benefited them and improved social welfare beyond just shareholder aims.

\section{Econometric Strategy}

We examine the merger's impact on a wide range of inputs and outcomes. For most measures, we assess their changes at target and acquirer hospitals from before to after the merger relative to a comparison group of for-profit hospitals. To implement this approach, we estimate a regression using annual observations of acquirer and target hospitals as well as other for-profit facilities, excluding hospitals acquired by the chain after the focal merger because of their unclear treatment status.

Specifically, we estimate:

$$
y_{h t}=\alpha_{t}+\delta_{h}+\beta_{A} \text { acquirer }_{h} \times \text { post }_{t}+\beta_{T} \text { target }_{h} \times \text { post }_{t}+X_{h t} \rho+\varepsilon_{h t},
$$

where $y_{h t}$ is the outcome of interest for hospital $b$ in year $t$, and $\alpha_{t}$ and $\delta_{h}$ are respectively year and hospital fixed effects. The interactions acquirer $_{h} \times$ post $_{t}$ and $\operatorname{target}_{h} \times$ post $_{t}$ denote respectively acquirer and target chain hospitals in the post-merger period. $X_{h t}$ are additional controls and $\varepsilon_{h t}$ is the error term. As additional controls, all specifications include interactions between the acquirer $_{h}$ and target $_{h}$ indicators and interim $_{t}$, an indicator for the merger year, to remove transitory implementation effects. In robustness specifications we also add geographic area-year effects (using Dartmouth Hospital Referral Regions as areas, see Center for the Evaluative Clinical Sciences, 1996).

The coefficients of interest are $\beta_{A}$, the post-merger change in the outcome for acquiring hospitals, and $\beta_{T}$, the change for target hospitals. They are identified by the relative trajectories of 
acquiring and target hospitals vs. other for-profit facilities. The key identifying assumption is that absent the merger, the two chains' outcomes would have evolved in parallel to other for-profit facilities. We back this assumption with event study plots showing that outcomes were on parallel trends before the merger and by showing the robustness of our estimates to additional statistical controls.

\section{Data}

To build the sample, we produced a list of hospitals in the acquirer and target chains immediately before the merger using the American Hospital Association (AHA) survey, which collects extensive data annually on all hospitals in the US (AHA 2015). We used the same survey to assemble the comparison group, for-profit facilities. Using public records, we identified hospitals acquired by the focal chain in later years and excluded them, as well as hospitals in the target chain that were immediately divested following the merger. We focus on hospitals open throughout the analysis period (they appear in the AHA data in our first and final years of analysis). Data on hospital inputs and outputs are drawn from the following sources:

Factor Inputs: The 2003-2014 HIMSS surveys include adoption of EMRs and related computer systems (Dorenfest Institute 2015). We capture physician labor inputs in the form of physician flows from 2003-2014 Medicare inpatient and emergency department claims (CMS 2015a, CMS 2015b). Hospitals' capital investments come from Medicare hospital cost reports (CMS 2020) and full-time equivalent (FTE) employment from the AHA surveys. Over half of the target hospitals did not report capital investment in 2003, so we analyze this variable from 2004 onwards.

Management Inputs: We collected data on management, which we treat as an input into hospital production, in two forms. First, we tracked the movement of hospital CEOs before and after the acquisition using the 2004-2014 AHA surveys. Second, we conducted surveys of hospital managers 
using the World Management Survey (Bloom et al., 2020; Bloom and Van Reenen, 2007) in target and acquirer facilities in 2015.

Outputs: Financial outcomes are from the Medicare hospital cost reports spanning calendar years 2003-2014. We assess clinical outcomes in the form of survival and readmission rates using Medicare inpatient claims from 2003-2014.

Table 1 presents descriptive statistics on acquirer, target, and other for-profit facilities in the year before acquisition. As noted, acquirer hospitals tended to be smaller and more rural than target facilities and other for-profits. Acquirer facilities tended to use a distinct EMR vendor; its use was rare among other for-profits, and it was never used by the target. Physician churn rates, defined as the combined rates of physician entry and exit (described in detail in the subsequent section), were similar across the groups. The acquirer had less FTE hospital staff at its hospitals than did other for-profits, while target hospitals tended to employ more staff. Capital investment was similar at acquirer and other for-profit facilities but lower at targets. The acquirer had notably higher CEO churn than the target and other for-profits; in particular, nearly one-third of acquirer hospitals gained a new CEO in that year. Profit margins were poorer at acquirer hospitals than other for-profits; in contrast, target hospitals tended to be more profitable. Clinical performance as given by risk-adjusted patient survival and readmission rates were also somewhat poorer for acquirer hospitals, while target facilities and other for-profits performed better on this dimension.

\section{Results}

\subsection{Input Use}

We first explore whether and how hospitals' use of key inputs changed after the merger. Our foci reflect the mechanisms by which the acquirer claimed it would improve target facility performance. In the appendix, we show our findings are similar restricting to observations with complete data on all 
inputs and financial measures (Table A1), as well as to adding area-year controls to address concerns that input utilization was on differing trajectories in acquirer or target hospital geographic areas compared to areas with other for-profits (Table A2).

\subsubsection{Electronic Medical Records}

EMRs represent a key capital input into the hospital production process, and a major planned initiative of the acquiring firm was to install its EMR system at targets. Panel A of Figure 1 shows how the fraction of hospitals with the system evolved. Before the merger, the acquirer was still rolling the system out internally. Three years pre-merger, $70 \%$ of its hospitals used the system; this share rose to $86 \%$ by the time of the merger. As expected, no target hospital had installed EMRs from this niche vendor before the merger, but the rollout began soon after. Progress was modest at first, then accelerated. Three years after the merger, a third of target hospitals had the EMR system. By the fifth year adoption had risen to just under 58\%, where it plateaued. In target hospitals, we also noted a pattern of dropping chain-specific EMRs during the post-merger period: 59\% of targets dropped a vendor they uniquely used while 34\% dropped a self-developed EMR system.

These patterns strongly suggest that the target hospitals harmonized their EMR system with the acquirer's. To formally verify this insight, we calculate for each hospital in each year the average EMR discordance between it and the acquirer hospitals. Our measure of discordance between two hospitals is the count of vendors that have only been adopted by one hospital and not both. Row 1 of Table 2 presents regression results with this average as the outcome. They confirm the visual findings: the target-acquirer discordance dropped sharply after the merger, relative to the same metric between other for-profits and the acquirer. The two-unit decline is equivalent to, for example, the target chain de-adopting its own system and adopting the acquirer's system. Panel B of Figure 1 
presents an event study version of this regression and shows that EMR harmonization begins shortly after the merger. ${ }^{3}$

\subsubsection{Physician Flows}

According to the acquirer's filings around the time of the merger, they expected gains from expanding patient volume through aggressive recruitment and retention of new physicians, leveraging a centralized physician recruitment program they previously used successfully in legacy hospitals. To examine whether the merger led to the intended change in physician labor flows, we track physicians' hospital arrivals and departures using Medicare emergency department and inpatient claims. ${ }^{4}$

We focus on physicians who are entering (they appear at the focal hospital in year $t$ but not $t-1$ ) and exiting (at the hospital in $t-1$ but not $t$ ). The hospital's entry rate is defined as its charges for patients treated by entering physicians in year $t$ scaled by the hospital's average total charges for all patients in years $t$ and $t-1$. Its exit rate is its charges for patients treated by exiting physicians in $t-1$ divided by the same denominator. We also compute the churn rate as the sum of entry and exit rates. (Appendix A).

The acquirer's stated aims imply a post-merger rise in churn at target hospitals. The event study analysis in Panel C of Figure 1 confirms that physician exit rates followed similar trajectories at acquirer and target hospitals as other for-profits in the years leading up to the merger (Panel A of Figure A2 shows the same result for physician entry). Trajectories were also similar after the merger, with one exception. Physician exit is statistically significantly elevated for one year after the merger in

\footnotetext{
${ }^{3}$ For symmetry with the other analyses, these exhibits also plot acquirer effects. When the focal hospital is in the acquirer chain, the outcome measures its discordance from other hospitals in its own chain. We generally find negative acquirer effects, indicating that the acquirer also harmonized EMR systems across its legacy hospitals.

4 We identify physicians using the attending physician listed on each claim. Claims data transitioned to a new physician identifier the year after the merger, disrupting our ability to calculate flows (we cannot reliably crosswalk old and new identifiers). We therefore omit that year from all analyses of physician flows.
} 
target hospitals before falling again, suggesting that the acquirer may have briefly been able to move this outcome. There is no corresponding increase in entry, however, and averaging over the entire post-merger period, we detect no significant merger effects on either acquirer or target flow rates (Table 2 rows 2-4).

\subsubsection{Employment and Capital Investments}

We next consider whether the acquisition was followed by significant changes in other labor inputs measured as FTE employment or capital investments (Table 2, rows 5 and 6). FTEs fall significantly at acquirer hospitals relative to other for-profits after the merger, while capital investment falls at target hospitals. The event study illustrates the dynamics of these results. Panel B of Figure A2 shows that FTEs at hospitals in the merged chain begin a steady decline after the merger, especially at acquirer facilities. Panel C shows that capital investments in acquirer hospitals have a large, significant, and transitory decline in the year of the merger, suggesting that these facilities engaged in short-term divestments. In contrast, post-merger cutbacks in capital investments at target facilities are more persistent.

\subsubsection{C-Suite Flows}

We examined the extent to which the acquisition led to the replacement of target hospitals' CEOs and whether the incoming executives were drawn from the pool of managers who had worked in the past with the acquirer. To do so, we gathered information on appointed CEOs using the AHA hospital survey, focusing on the sample of acquirer and target hospitals at the time of the merger with nonmissing CEO names for at least 10 years over the period spanning 2004 and 2014 (58 acquirer hospitals and 37 target hospitals). We then used the full AHA panel data to reconstruct the careers of each person who held a CEO position for at least one year in one of these hospitals before or after the 
merger. We determined whether they were CEO of another hospital prior to their appointment and, if so, whether that hospital belonged to the target, the acquirer, or neither. We identified 295 acquirer and target CEOs during the analysis period. ${ }^{5}$

There is frequent CEO turnover in this sample. From 2004 to 2014, an average of 29\% of acquirer hospitals, $20 \%$ of target hospitals, and $22 \%$ of other for-profit hospitals experience a CEO change each year. These turnover rates for acquirer facilities are elevated relative to other industries and other hospital contexts internationally. ${ }^{6}$ Turnover rates varied more over time in the acquirer and target chains than in other for-profit facilities (Figure A3). In the year before acquisition, the CEO turnover rate at targets $(22 \%)$ was similar to the rate at other for-profits $(24 \%)$, but it rose substantially in the year after the acquisition, with another wave two years later. Acquirer hospitals also saw waves of turnover during this time, while other for-profit hospitals had stable turnover rates through the period. We also see a change in the provenance of CEOs appointed post-merger in target hospitals (Figure 2 and Table A3). Before the acquisition, newly appointed CEOs at target hospitals were either CEOs at other target hospitals, CEOs at hospitals outside the acquiring chain, or not a CEO at any hospital. Soon after the acquisition, however, there began a steady influx of managers who had been CEOs in the acquirer's hospitals. We also found that many of the new managers had been previously employed in an acquirer hospital in a non-CEO role. ${ }^{7}$

\footnotetext{
${ }^{5}$ During the analysis period, these CEOs hold a CEO position at an average of 1.44 hospitals for managers ever employed by the acquiring chain and 1.43 hospitals for managers ever employed in the target chain. Average tenure was 2.74 years at acquirer hospitals and 3.51 years at target hospitals (see Table 1 for average CEO tenure in 2006, the year before the merger). As a comparison, these averages are 1.30 hospitals and 3.35 years for managers employed at the other 451 forprofit hospitals for which we could compute this information in the sample period.

${ }^{6}$ For example, English NHS hospital CEOs spend an average of 3.7 years per hospital and 20\% of hospitals have a newly appointed CEO in a given year (Janke et al., 2019); at Fortune 500 firms, 17\% appoint a new CEO annually from 2000 to 2007 (Kaplan and Minton, 2012).

7 We conducted internet searches, including press releases and LinkedIn resumes, to assess the work histories of the 26 new CEOs at target hospitals in the three calendar years after the merger. We found histories for 23; 14 had been employed in a non-CEO position in an acquirer hospital, while 7 came from the target's hospitals. We also investigated the qualifications of new CEOs at the targets and found that the share with clinical qualifications (i.e. graduate medical or nursing degrees) declined from $81 \%$ before the merger to $63 \%$ after.
} 


\subsubsection{Management Practices}

We now turn to an aspect of acquisitions that is usually unobserved: whether the merger resulted in the harmonization of managerial practices. The acquirer referred in public communications to its ability to disseminate managerial best practices across its hospitals, such as data standardization and evidence-based methods in clinical care, to drive clinical and financial performance post acquisition.

To examine this claim, we collected data on the managerial processes used in subsets of both legacy and acquired hospitals using the World Management Survey (WMS; c.f. Bloom and Van Reenen, 2007). This instrument has been used to measure the adoption of a set of basic managerial practices in private and public sector organizations, including in hospitals (Bloom et al., 2020, 2015, 2012). The health care version of the survey focuses on 20 practices related to the management of operations, monitoring, targets and human resources. Each practice is scored on a 1-5 scale, with higher values denoting a more intensive and systematic adoption. The management index is the raw average of scores across the 20 questions.

We ran the data collection in 2015 as part of a research study conducted with the support of the acquirer's top management team across 23 hospitals within the acquirer network (11 acquirer and 12 target hospitals). Appendix B provides more details on the methodology, data collection, and measurement approach. We report the average and standard deviations of hospital-level management scores for the merged chain as well as the acquirer and target subsets. As a benchmark, we also estimate the within-chain variation in scores at US hospitals using WMS data collected in 2009 on a broader sample of facilities (Bloom et al., 2012). We restrict to hospitals that were part of chains other than the target or acquirer, estimate a model with chain random effects, and report the standard deviation 
of the residual. ${ }^{8}$ Together, these data allow us to measure the extent to which the acquirer was able to enforce a common set of management practices across its hospitals relative to other US hospital chains. ${ }^{9}$

The analysis is in Table 3. Three results are of note. First, WMS sample hospitals have significantly higher management scores than both acquirer hospitals $(\not<0.001)$ and target hospitals $(p<0.01)$. Second, within-chain variation in management scores in the WMS sample is higher than variation across target hospitals $(p=0.01$ ) and across acquirer hospitals (significant at the $10 \%$ level, $p=0.06)$. Finally, though the sample is relatively small for this comparison, target hospitals appear similar to the acquirer hospitals both in terms of average management scores and variations thereof. We cannot reject equality of the means and standard deviations of the two groups. In other words, while not necessarily converging to the industry average level of managerial quality (according to WMS scoring), the chain was able to implement a common set of practices across its hospitals some years after the acquisition.

\subsection{Financial Outcomes}

We begin our investigation of the merger's effects on financial performance by focusing on hospital costs and prices, the subject of much of the prior merger literature. Table 2 reports the results. Row 7 shows the merger raised costs per inpatient discharge by $10 \%$ at acquirer facilities, an economically large and statistically significant change, but had no detectable impact on costs at target hospitals. ${ }^{10}$ In

\footnotetext{
8 The sample is 157 hospitals across 95 chains; for 29 of the chains we have data on multiple hospitals.

${ }_{9}^{9}$ Given the sample size, we limit the analysis to the comparison of the management scores without controls for hospital characteristics, and we do not restrict the WMS sample to only for-profit facilities. Limiting the WMS sample to for-profits $(N=28)$ yields qualitatively similar results, although as expected they are less precise.

${ }_{10}$ We investigated the sources of these cost increases at acquirer hospitals by analyzing finer categorizations. Of the seven broad cost categories consistently reported in the HCRIS data, we only detected increases in one, general service costs, which accounts for $60 \%$ of costs at acquirer facilities. Within that category, we saw statistically significant increases in the following cost lines (the finest level reported): central services/supply, medical records, nursing administration, pharmacy,
} 
row 8, we analyze the merger's effect on estimates of hospital prices for non-Medicare patients (our approach is similar to that of Dafny, 2009 and Garmon, 2017; see Appendix C). Point estimates show a statistically significant and economically meaningful rise in prices at acquirer facilities of $37 \%(32 \log$ points). The value at target facilities is $12 \%$ (11 log points) but not statistically significant. Row 9 reports that revenues per inpatient discharge rose significantly at acquirer facilities, by $5 \%$. We do not find a significant change in revenues at target hospitals. Overall, cost increases outpaced revenue growth at acquirer facilities, resulting in a statistically significant deterioration in hospital profit margins (revenues less costs, divided by revenues) of 3.3 percentage points, as shown in row 10 .

We investigate the profit margins' trajectories in more detail in the event study depicted in Panel D of Figure 1. It shows flat pre-trends for acquirer hospitals and, if anything, slight upward (though not pointwise statistically significant) pre-trends for target facilities. After the merger, however, there is divergence. While target hospitals saw at best a transitory and statistically insignificant improvement, profitability at the hospitals owned by the acquiring firm prior to the merger slipped continuously. Relative to other for-profit hospitals, profitability at these facilities declined by just under 1 percentage point per year. These visual patterns align with the point estimates in Table 2.

The results were similar restricting to hospital-years with data on all inputs and financial measures, though the price and revenue rises for acquirer hospitals were attenuated (Table A1). Findings were also qualitatively similar when we augmented this model with area-by-year effects to account for the potential for the focal chains to locate in areas on differing profitability trajectories (Table A2). One subtle difference is that the acquirer profitability effect attenuates, indicating that the profitability drop of these hospitals was due partly to the declining profitability of their local areas.

capital equipment, and laundry (Table A4). A key caveat is that values for these narrow cost components are often zero, raising the possibility of mismeasurement. 


\subsection{Clinical Outcomes}

We now examine key clinical outcomes before and after the acquisition: patient survival and readmission. ${ }^{11}$ Using Medicare inpatient claims and enrollment files, we develop four cohorts of emergency patients for whom these outcomes are commonly studied and particularly relevant: acute myocardial infarction (or heart attack), heart failure, pneumonia, and stroke. These are all serious health conditions with significant risk of death and rehospitalization. We focus on hospital-level survival and readmission rates for patients in these cohorts because they are tracked by CMS in its hospital performance incentive programs and are publicly reported as quality measures on the CMS Hospital Compare website. Patient survival is also a key outcome of clinical trials for emergency conditions like the ones we study (see e.g. Keeley et al., 2003), and high readmission rates are widely regarded as a sign of low-quality care and have become an important input in hospital pay-forperformance schemes (Gupta, 2020; Jencks et al., 2009).

The cohorts consist of inpatient admissions for the given condition. We exclude admissions if the patient was previously hospitalized for the condition within the past year to remove follow-up care. We track if each patient survives 30 days from admission or is readmitted to any hospital within 30 days of discharge. The data also include indicators for patient demographics (age-race-sex interactions) and information to adjust for patient risk factors and illness severity (we construct indicators for having a diagnosis of 25 key illnesses during an inpatient stay in the past year). ${ }^{12}$ Studies have cross-validated this approach to estimating hospital quality for emergency patients and found it

\footnotetext{
11 We adapt our approach from Chandra et al. (2016), which provides full details on cohort assembly, survival and readmission measurement, and construction of illness histories (risk adjusters). We note two key changes from its methods: we use different three-year periods (described in the text), and we construct a stroke patient cohort instead of a hip and knee replacement cohort.

${ }^{12}$ In the stroke cohort, we also control for ischemic vs. hemorrhagic stroke.
} 
correlates strongly with quality as measured by patients quasi-randomized to hospitals (Doyle et al., 2019; Hull, 2020)

To improve precision, we group years into four periods: 2004-2006 (pre-merger), 2008-2011 (early post-merger), and 2012-2014 (late post-merger); we omit 2007 (the merger year) to remove temporary implementation effects. Then, for each cohort $c$ and period $t$, we estimate clinical outcomes (survival rates, readmission rates) for all hospitals $h$, adjusting for differences in patient severity. Specifically, we separately regress patient survival and readmission rates on hospital fixed effects, patient demographics, and patient illness histories. We extract the estimated hospital fixed effects and define them as the adjusted outcomes measures $\left(o_{c h t}\right)$; they capture hospital-level survival and readmission rates purged of the observed aspects of patient severity.

We then augment equation (1) to produce the following "stacked" regression model to assess the acquisition's impacts on our severity-adjusted clinical outcomes:

$$
\begin{aligned}
o_{c h t}=\alpha_{c t}+ & \delta_{c h}+\beta_{A} \text { acquirer }_{h} \times \text { post }_{t}+\beta_{T} \text { target }_{h} \times \text { post }_{t}+X_{c h t} \rho_{c} \\
& +\varepsilon_{c h t},
\end{aligned}
$$

where $X_{\text {cht }}$ allows for additional controls for robustness analyses.

Row 11 of Table 2 reports the survival results. They do not indicate any post-merger improvement in patient survival at acquirer or target hospitals relative to other for-profits. The estimate for target hospitals indicates a statistically insignificant 0.2 percentage point drop in average survival rates off a base of $89 \%$. The 0.6 percentage point decline in survival at the acquirer's hospitals is larger in magnitude but also statistically insignificant. These estimates show that if anything, survival outcomes deteriorated after the merger, particularly at acquirer facilities.

Row 12 of Table 2 shows the readmission rate outcomes. Target hospitals saw a small and statistically insignificant rise in readmission rates after the merger relative to other for-profits. Acquirer hospitals saw a modest 0.7 percentage point drop off a pre-merger average of $15 \%$. It is notable that 
this is the one beneficial result (financial or clinical) of the merger that we find among the acquiring chain's hospitals. However, given the similarly-sized estimated decline in survival, it is hard to conclude clinical outcomes improved overall for these hospitals.

In Table A2, we add cohort-area-period fixed effects to capture flexible trends across geographies. Results are qualitatively unchanged. The survival rate drop at acquirer hospitals becomes significant at the $10 \%$ level, while the fall in acquirer hospitals' readmission rates becomes statistically insignificant due to a reduction in statistical precision.

\section{Discussion and Conclusion}

Mergers are a critical part of the health care landscape and the economy more generally. Despite their importance, there are significant gaps in the literature regarding the organizational mechanisms that drive merger effects. We focus here on a set of acquisitions by a large hospital chain as a means of gaining deeper insight into merger outcomes and the factors that drive them. By focusing on hospitals we can employ rich data on inputs and outcomes tracked in existing and regularly collected administrative and survey data. We augment these data with management surveys that provide a window into the firm's organization. This approach lets us look deeply into the effects of these hospital acquisitions on the firms involved and on consumers (patients).

We find that the acquirer was able to exert influence on intermediate input use at target hospitals. In particular, it harmonized their health IT systems with its own and sent its personnel to manage the acquired facilities. Target and acquirer hospitals came to use similar managerial practices, although not necessarily high-quality ones. Yet, over the seven years following the merger, there is little sign that clinical or financial performance improved at targets. Meanwhile, financial outcomes at facilities already part of the acquirer chain deteriorated almost continuously, a potential unintended consequence of shifting resources to targets aligning with the "new toy" effect of Schoar (2002), who 
suggested mergers can damage the performance of incumbent divisions due to resource outflows to newly acquired entities.

The literature has largely and appropriately focused on estimating the average effect of mergers. This approach aggregates together a variety of mergers in which acquirers may have intended to influence performance through differing organizational channels. As a consequence, this work does not typically uncover the mechanisms driving merger outcomes. For example, when mergers fail to generate benefits on average, it is hard to know whether this failure reflects poor implementation of useful changes, good implementation of ineffective changes, or no implementation of changes at all (Gibbons and Henderson, 2012).

Our approach addresses the mechanisms issue by leveraging a mega-merger as a case study, benchmarking the changes we see at the target and acquiring hospitals against those the acquiring firm planned to implement. We evaluate whether their intended organizational changes materialized and whether they led to improved outcomes for the firms and patients. We demonstrate that the promised merger efficiencies ultimately fail to appear even after an extended period. The results emerging from this analysis connect to work highlighting the role of managerial pathologies in explaining performance differences across organizations, as in Gibbons and Henderson (2012).

Our findings provide new insights on mergers in health care. Future research that similarly opens the black box of organizations in health care and other sectors can improve our understanding of merger mechanisms, systematically studying how management processes and the managers who influence them flow within the firm.

We note a key puzzle: the organization we study was financially motivated to change and improve, yet the merger led to no clear benefits in hospital performance. In this way, the effects closely align with existing findings that hospital mergers fail to improve patient care. Our evidence on mechanisms suggests that of all the levers it could have moved to raise performance, the chain exerted 
its strongest influence on those more straightforward to implement but likely to have little payoff absent changes in complementary organizational factors: it purchased new health IT and moved around its CEOs. It is particularly hard to imagine substantial benefits from these interventions given that pre-merger outcomes at the target facilities tended to be better than those at acquirer facilities.

Regarding merger policy, our findings provide a new perspective for antitrust authorities evaluating mergers' claimed efficiencies. For example, our results highlight the value of taking a view that considers the stated organizational aims of the merger, how the firm intends to implement these aims, whether the stated plans are realistic given the managerial capabilities of the organizations involved in the merger, and whether these changes are likely to yield performance improvements. Such an approach would sharpen the assessment of efficiency claims made in every merger, debunking those that are implausible (and therefore unlikely to offset possible anticompetitive outcomes) and helping to identify "good mergers" (Dafny and Lee, 2015).

As an example from the acquisition we evaluate here, a critical review of the acquirer's organizational capabilities might have raised questions about their fit with the ambitious stated aims of the merger, which required the targets to quickly and productively adopt the acquirer's technologies and practices. Moreover, this view might have challenged the notion that the acquirer's organization could implement more systematic change-management programs at the targets rather than merely transferring existing personnel to these facilities. Taken together, these viewpoints would paint a more skeptical picture of the merger's potential to improve quality and cut costs. 


\section{References}

American Hospital Association, 2015. AHA Annual Survey [Dataset].

Beaulieu, N.D., Dafny, L.S., Landon, B.E., Dalton, J.B., Kuye, I., McWilliams, J.M., 2020. Changes in Quality of Care after Hospital Mergers and Acquisitions. N Engl J Med 382, 51-59. https://doi.org/10.1056/NEJMsa1901383

Bloom, N., Genakos, C., Sadun, R., Van Reenen, J., 2012. Management practices across firms and countries. Academy of management perspectives 26, 12-33.

Bloom, N., Lemos, R., Sadun, R., Van Reenen, J., 2020. Healthy Business? Managerial Education and Management in Health Care. Review of Economics and Statistics 102, 506-517. https://doi.org/10.1162/rest_a_00847

Bloom, N., Propper, C., Seiler, S., Van Reenen, J., 2015. The Impact of Competition on Management Quality: Evidence from Public Hospitals. The Review of Economic Studies 82, 457-489. https://doi.org/10.1093/restud/rdu045

Bloom, N., Van Reenen, J., 2007. Measuring and Explaining Management Practices Across Firms and Countries. The Quarterly Journal of Economics 122, 1351-1408. https://doi.org/10.1162/qjec.2007.122.4.1351

Burns, L.R., McCullough, J.S., Wholey, D.R., Kruse, G., Kralovec, P., Muller, R., 2015. Is the System Really the Solution? Operating Costs in Hospital Systems. Med Care Res Rev 72, 247-272. https://doi.org/10.1177/1077558715583789

Capps, C., 2005. The quality effects of hospital mergers, Discussion paper. U.S. Department of Justice, Antitrust Division.

Center for the Evaluative Clinical Sciences, 1996. The Dartmouth Atlas of Health Care, The dartmouth atlas of health care. American Hospital Publishing.

Centers for Medicare and Medicaid Services, 2020. Healthcare Cost Report Information System (HCRIS) [Dataset].

Centers for Medicare and Medicaid Services, 2015a. Medicare Inpatient Research Identifiable File [Dataset].

Centers for Medicare and Medicaid Services, 2015b. Medicare Outpatient Research Identifiable File [Dataset].

Chandra, A., Finkelstein, A., Sacarny, A., Syverson, C., 2016. Health Care Exceptionalism? Performance and Allocation in the US Health Care Sector. American Economic Review 106, 2110-2144. https://doi.org/10.1257/aer.20151080

Cooper, Z., Craig, S.V., Gaynor, M., Van Reenen, J., 2019. The Price Ain't Right? Hospital Prices and Health Spending on the Privately Insured*. The Quarterly Journal of Economics 134, 51107. https://doi.org/10.1093/qje/qjy020

Dafny, L., 2009. Estimation and Identification of Merger Effects: An Application to Hospital Mergers. The Journal of Law and Economics 52, 523-550. https://doi.org/10.1086/600079

Dafny, L.S., Lee, T.H., 2015. The Good Merger. N Engl J Med 372, 2077-2079. https://doi.org/10.1056/NEJMp1502338

Dorenfest Institute for Health Information, 2015. HIMSS Analytics Database [Dataset].

Doyle, J., Graves, J., Gruber, J., 2019. Evaluating Measures of Hospital Quality: Evidence from Ambulance Referral Patterns. The Review of Economics and Statistics 101, 841-852. https://doi.org/10.1162/rest_a_00804

Garmon, C., 2017. The accuracy of hospital merger screening methods. The RAND Journal of Economics 48, 1068-1102. https://doi.org/10.1111/1756-2171.12215

Gaynor, M., 2020. What to Do about Health-Care Markets? Policies to Make Health-Care Markets Work (Policy Proposal No. 2020-10). The Hamilton Project. 
Gaynor, M., Ho, K., Town, R.J., 2015. The Industrial Organization of Health-Care Markets. Journal of Economic Literature 53, 235-284. https://doi.org/10.1257/jel.53.2.235

Gibbons, R., Henderson, R., 2012. What Do Managers Do?, in: GIBBONS, R., ROBERTS, J. (Eds.), The Handbook of Organizational Economics. Princeton University Press, pp. 680-731.

Gowrisankaran, G., Nevo, A., Town, R., 2015. Mergers When Prices Are Negotiated: Evidence from the Hospital Industry. American Economic Review 105, 172-203. https://doi.org/10.1257/aer.20130223

Gupta, A., 2020. Impacts of Performance Pay for Hospitals: The Readmissions Reduction Program.

Hull, P., 2020. Estimating Hospital Quality with Quasi-experimental Data [WWW Document]. URL https://about.peterhull.net/wp

Janke, K., Propper, C., Sadun, R., 2019. The Impact of CEOs in the Public Sector: Evidence from the English NHS (No. w25853). National Bureau of Economic Research, Cambridge, MA. https://doi.org/10.3386/w25853

Jencks, S.F., Williams, M.V., Coleman, E.A., 2009. Rehospitalizations among Patients in the Medicare Fee-for-Service Program. N Engl J Med 360, 1418-1428. https://doi.org/10.1056/NEJMsa0803563

Kaplan, S.N., Minton, B.A., 2012. How Has CEO Turnover Changed?: How Has CEO Turnover Changed? Int. Rev. Finan. 12, 57-87. https://doi.org/10.1111/j.1468-2443.2011.01135.x

Keeley, E.C., Boura, J.A., Grines, C.L., 2003. Primary angioplasty versus intravenous thrombolytic therapy for acute myocardial infarction: a quantitative review of 23 randomised trials. The Lancet 361, 13-20. https:/ / doi.org/10.1016/S0140-6736(03)12113-7

Kessler, D.P., McClellan, M.B., 2000. Is Hospital Competition Socially Wasteful? The Quarterly Journal of Economics 115, 577-615. https://doi.org/10.1162/003355300554863

McConnell, K.J., Lindrooth, R.C., Wholey, D.R., Maddox, T.M., Bloom, N., 2013. Management Practices and the Quality of Care in Cardiac Units. JAMA Intern Med 173, 684. https://doi.org/10.1001/jamainternmed.2013.3577

Romano, P.S., Balan, D.J., 2011. A Retrospective Analysis of the Clinical Quality Effects of the Acquisition of Highland Park Hospital by Evanston Northwestern Healthcare. International Journal of the Economics of Business 18, 45-64. https://doi.org/10.1080/13571516.2011.542955

Schmitt, M., 2017. Do hospital mergers reduce costs? Journal of Health Economics 52, 74-94. https://doi.org/10.1016/j.jhealeco.2017.01.007

Schoar, A., 2002. Effects of Corporate Diversification on Productivity. The Journal of Finance 57, 2379-2403. https://doi.org/10.1111/1540-6261.00500

Tenn, S., 2011. The Price Effects of Hospital Mergers: A Case Study of the Sutter-Summit Transaction. International Journal of the Economics of Business 18, 65-82. https://doi.org/10.1080/13571516.2011.542956

Tsai, T.C., Jha, A.K., 2014. Hospital Consolidation, Competition, and Quality: Is Bigger Necessarily Better? JAMA 312, 29. https://doi.org/10.1001/jama.2014.4692 


\section{Tables}

Table 1: Descriptive Statistics on Acquirer, Target, and Other For-Profit Hospitals in 2006

\begin{tabular}{|c|c|c|c|}
\hline & $\begin{array}{c}\text { (1) } \\
\text { Acquirer } \\
\text { Hospitals }\end{array}$ & $\begin{array}{c}(2) \\
\text { Target } \\
\text { Hospitals }\end{array}$ & $\begin{array}{c}(3) \\
\text { Other For- } \\
\text { Profits }\end{array}$ \\
\hline$\overline{\text { Beds }}$ & $\begin{array}{l}119.1 \\
(79.7)\end{array}$ & $\begin{array}{l}171.5 \\
(81.4)\end{array}$ & $\begin{array}{c}175.4 \\
(144.2)\end{array}$ \\
\hline Rural & 0.667 & 0.250 & 0.234 \\
\hline Has acquirer EMR vendor & 0.860 & 0.000 & 0.063 \\
\hline Physician churn rate & $\begin{array}{c}0.084 \\
(0.058)\end{array}$ & $\begin{array}{c}0.078 \\
(0.055)\end{array}$ & $\begin{array}{c}0.087 \\
(0.076)\end{array}$ \\
\hline FTEs & $\begin{array}{c}481.9 \\
(329.0)\end{array}$ & $\begin{array}{c}729.1 \\
(382.7)\end{array}$ & $\begin{array}{c}660.8 \\
(582.2)\end{array}$ \\
\hline Capital investments (\$millions) & $\begin{array}{c}5.471 \\
(6.779)\end{array}$ & $\begin{array}{c}4.787 \\
(13.26)\end{array}$ & $\begin{array}{c}5.625 \\
(7.568)\end{array}$ \\
\hline Tenure of CEO in 2006 in years & $\begin{array}{c}2.103 \\
(0.852)\end{array}$ & $\begin{array}{c}2.405 \\
(0.832)\end{array}$ & $\begin{array}{c}2.321 \\
(0.839)\end{array}$ \\
\hline Has a new CEO in 2006 & 0.310 & 0.216 & 0.235 \\
\hline Profit margin & $\begin{array}{c}0.040 \\
(0.088)\end{array}$ & $\begin{array}{c}0.058 \\
(0.072)\end{array}$ & $\begin{array}{c}0.047 \\
(0.093)\end{array}$ \\
\hline Price index $($ mean $=100)$ & $\begin{array}{c}68.58 \\
(98.02)\end{array}$ & $\begin{array}{c}81.89 \\
(89.51)\end{array}$ & $\begin{array}{c}107.0 \\
(105.0)\end{array}$ \\
\hline Costs per inpatient $(\$)$ & $\begin{array}{c}6,659.8 \\
(1,573.9)\end{array}$ & $\begin{array}{c}8,142.9 \\
(1,989.3)\end{array}$ & $\begin{array}{c}8,280.2 \\
(3,008.2)\end{array}$ \\
\hline Revenue per inpatient (\$) & $\begin{array}{c}7,107.0 \\
(2,032.2)\end{array}$ & $\begin{array}{c}8,833.1 \\
(2,373.0)\end{array}$ & $\begin{array}{c}8,700.2 \\
(3,156.4)\end{array}$ \\
\hline Survival rate* & $\begin{array}{c}0.879 \\
(0.032)\end{array}$ & $\begin{array}{c}0.894 \\
(0.033)\end{array}$ & $\begin{array}{c}0.893 \\
(0.036)\end{array}$ \\
\hline Readmission rate* & $\begin{array}{c}0.150 \\
(0.031)\end{array}$ & $\begin{array}{c}0.126 \\
(0.019)\end{array}$ & $\begin{array}{c}0.138 \\
(0.030)\end{array}$ \\
\hline Hospitals & 57 & 36 & 350 \\
\hline
\end{tabular}

Notes: Values are averages (standard deviations in parentheses) for the given hospital characteristic in 2006, the year before the merger. Profit margins, capital investment, price index, costs, and revenues are winsorized at $5 \%$ on each side. Costs and revenue are measured in millions of dollars per inpatient (specifically, we divide costs and revenues by the measure of adjusted inpatient discharges laid out in Schmitt, 2017).

* 30-day survival or readmission rate for each hospital defined as the average of its rate in 2004-2006 across 4 cohorts (acute myocardial infarction, stroke, hip fracture, and pneumonia) after adjusting for patient risk factors as described in the main text. 
Table 2: Effects of Merger on Inputs, Financials, and Clinical Outcomes

\begin{tabular}{lccccc}
\hline & $\begin{array}{c}(1) \\
\text { Post } \times \\
\text { Acquirer }\end{array}$ & $\begin{array}{c}(2) \\
\text { Std } \\
\text { Error }\end{array}$ & $\begin{array}{c}(3) \\
\text { Post } \times \\
\text { Target }\end{array}$ & $\begin{array}{c}\text { Std } \\
\text { Error }\end{array}$ & N \\
\hline A. Inputs & & & & & \\
(1) No. of discordant EMR vendors & $-1.292^{* * *}$ & $(0.163)$ & $-2.047^{* * *}$ & $(0.247)$ & 3,538 \\
(2) Physician entry rate & 0.008 & $(0.011)$ & -0.002 & $(0.007)$ & 4,562 \\
(3) Physician exit rate & -0.001 & $(0.006)$ & 0.005 & $(0.004)$ & 4,562 \\
(4) Physician churn rate & 0.007 & $(0.011)$ & 0.003 & $(0.009)$ & 4,562 \\
(5) Log of FTE & $-0.091^{* * *}$ & $(0.027)$ & -0.029 & $(0.033)$ & 5,267 \\
(6) Log of 1+capital investment & 0.065 & $(0.084)$ & $-0.308^{* *}$ & $(0.125)$ & 4,863 \\
B. Financial Outcomes & & & & & \\
(7) Log of costs per inpatient & $0.095^{* * *}$ & $(0.020)$ & -0.003 & $(0.028)$ & 5,256 \\
(8) Log of price index & $0.318^{* *}$ & $(0.134)$ & 0.105 & $(0.092)$ & 4,879 \\
(9) Log of revenue per inpatient & $0.049^{* *}$ & $(0.022)$ & 0.015 & $(0.026)$ & 5,256 \\
(10) Profit margin & $-0.033^{* * *}$ & $(0.010)$ & 0.009 & $(0.010)$ & 5,242 \\
C. Clinical Outcomes & & & & & \\
(11) Survival & -0.006 & $(0.004)$ & -0.002 & $(0.004)$ & 5,610 \\
(12) Readmission & $-0.007^{* *}$ & $(0.003)$ & 0.005 & $(0.004)$ & 5,610 \\
\hline
\end{tabular}

Notes: This table displays differences-in-differences estimates of the merger effects on hospital inputs (Panel A), hospital financial outcomes (Panel B), and hospital clinical outcomes (Panel C). Each row represents a separate regression with the given measure as the dependent variable. Panels A and $\mathrm{B}$ report the results of estimating equation 1 , where each observation is a hospital-year and all regressions include hospital and year fixed effects. Panel $\mathrm{C}$ reports the results of estimating equation 2 , where each observation is a hospital-cohort-year group and all regressions include hospital-cohort and cohort-year group fixed effects (the cohorts are acute myocardial infarction, heart failure, pneumonia, and stroke and the year groups are 2004-2006, 2008-2011, and 2012-2014).

The measures are described in more detail in the text. In row 6 , we add unity to capital investment before taking the logarithm to accommodate hospitals with no investment in a year. In rows 7 and 9 , we divide costs and revenues by the adjusted inpatient discharges measure laid out in Schmitt (2017) before taking the logarithm. In rows $6-10$, we winsorize the measures by $5 \%$ on each side in each year. In rows 11 and 12, we derive the clinical measures from a first-stage patient-level regression of 30-day survival or readmission on hospital fixed effects, adjusting for patient demographics and risk factors. A separate first-stage regression is run for each cohort-year. The hospital fixed effects are extracted and can be interpreted as risk-adjusted survival or readmission rate for each cohort-hospital-year group. See text for details.

Robust standard errors clustered at the hospital level in parentheses. Effects significant at 10\% (*), 5\% $(* *)$, and 1\%(***). EMR: electronic medical record. 
Table 3: Management Practices

(1)

Average

Score
(2) Standard Deviation
(3)

Observations

(Hospitals)
(4)

Chains

$\begin{array}{lllll}\text { 1. Merged Chain } & 2.81(0.06) & 0.27(0.04) & 23 & 1 \\ \text { a. Acquirer } & 2.74(0.09) & 0.30(0.06) & 11 & \\ \text { b. Target } & 2.87(0.07) & 0.24(0.05) & 12 & \end{array}$

2. WMS sample

$3.08(0.04) \quad 0.43(0.03)$

157

91

Notes: Table reports the average and standard deviation of management scores across hospitals. Row 1 reports these statistics for the merged chain of acquirer and target hospitals. Rows $1 \mathrm{a}$ and $1 \mathrm{~b}$ report statistics for only acquirer and target hospitals, respectively. Row 2 reports statistics for the WMS sample; the reported standard deviation is within-chain. Standard deviations are derived from restricted maximum likelihood models (all rows) absorbing random effects for chains (row 2 only). See text for more details. Standard errors in parentheses. 


\section{Figures}

Figure 1: Visual Evidence of Merger Effects on Hospital Inputs and Outcomes

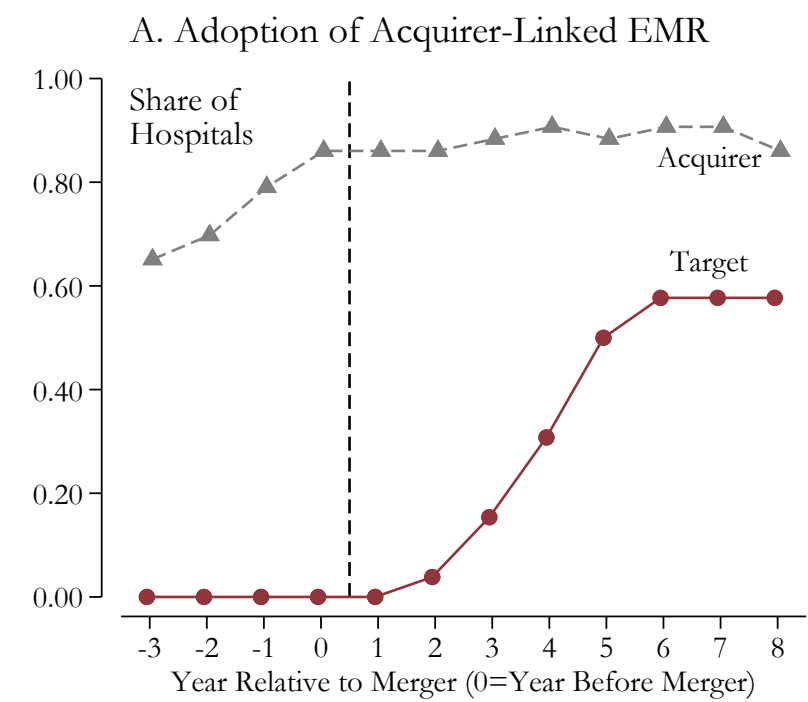

B. Event Study, No. of Discordant EMR Vendors

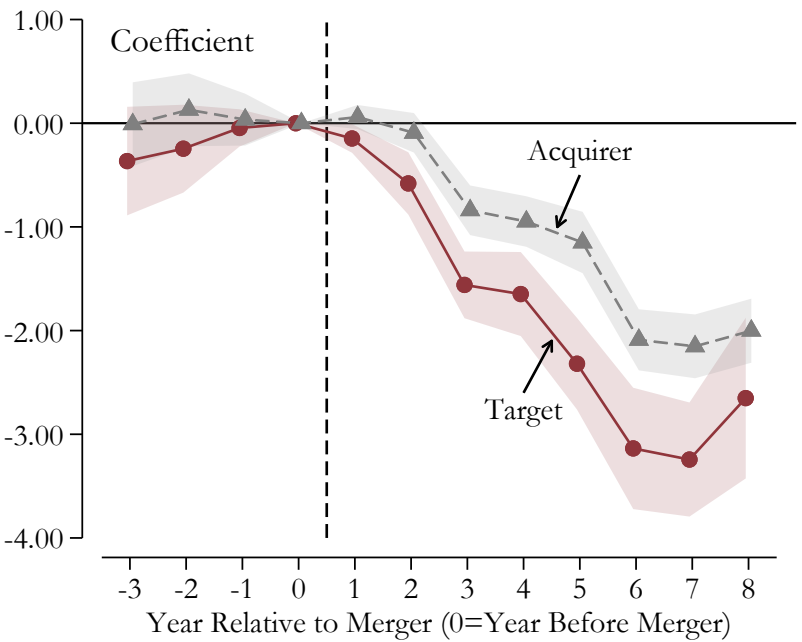

C. Event Study, Physician Exit Rate

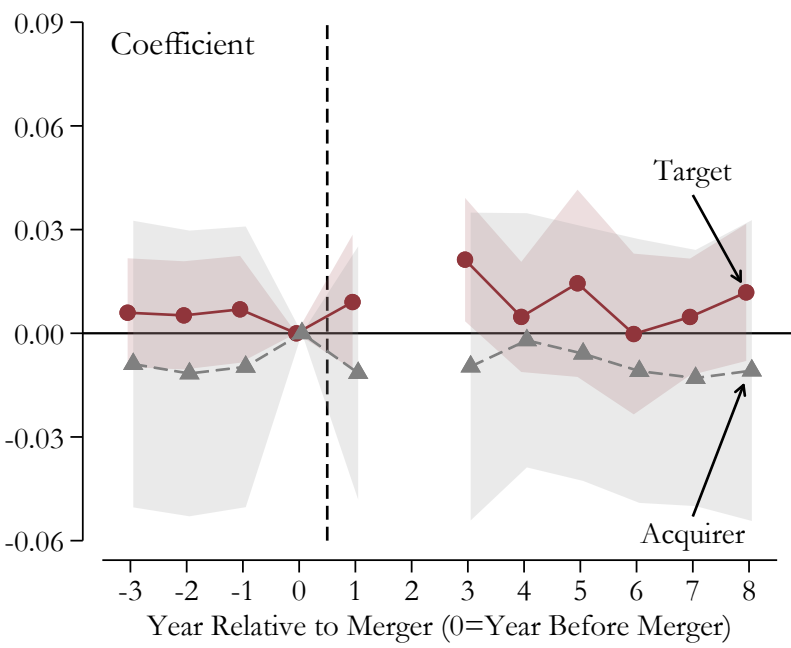

D. Event Study, Profit Margin

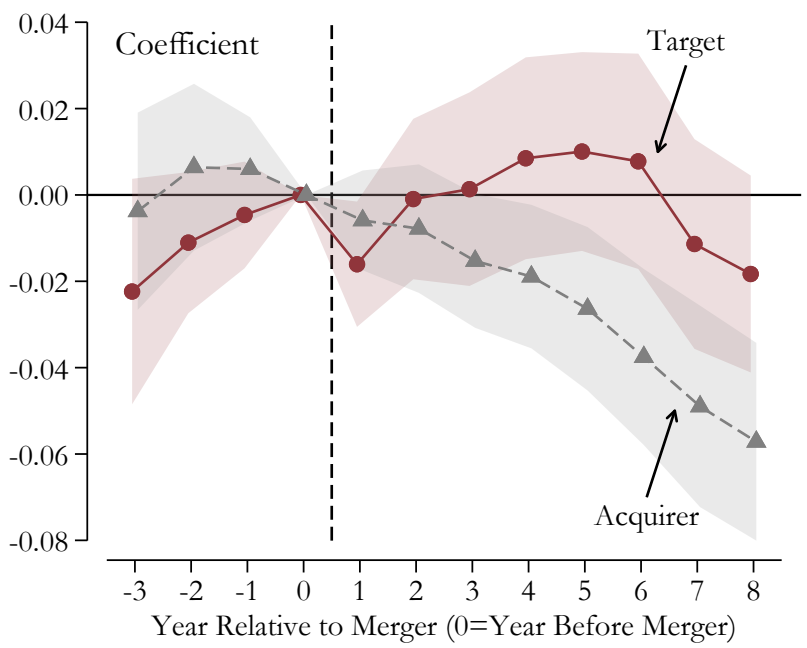

Notes: This figure shows visual evidence of the effects of the merger on hospital inputs and financial outcomes. Panel A depicts the share of hospitals in the two chains that have adopted an electronic medical record (EMR) vendor closely linked with the acquirer. The remaining panels present event study estimates of merger effects. Each estimates an event study version of equation (1) in which the outcome is the dissimilarity between the hospital's EMR and acquirer hospitals' (Panel B), the physician exit rate (Panel C), or the profit margin (Panel D). In Panel B, the outcome is the average number of EMR vendors with discordant adoption status between the focal hospital and hospitals in the acquirer chain. In Panel $\mathrm{C}$, we omit the year after the merger because physician flows are not observed in this year due to a physician identifier transition. In Panel D, profit margins are winsorized at $5 \%$ on each side in each year. See text for details.

We normalize the event study to the year before the merger. Shading represents $95 \%$ confidence intervals derived from robust standard errors clustered at the hospital level. The vertical dashed line depicts the time immediately before the merger. 
Figure 2: Origin of New CEOs among Target Hospitals

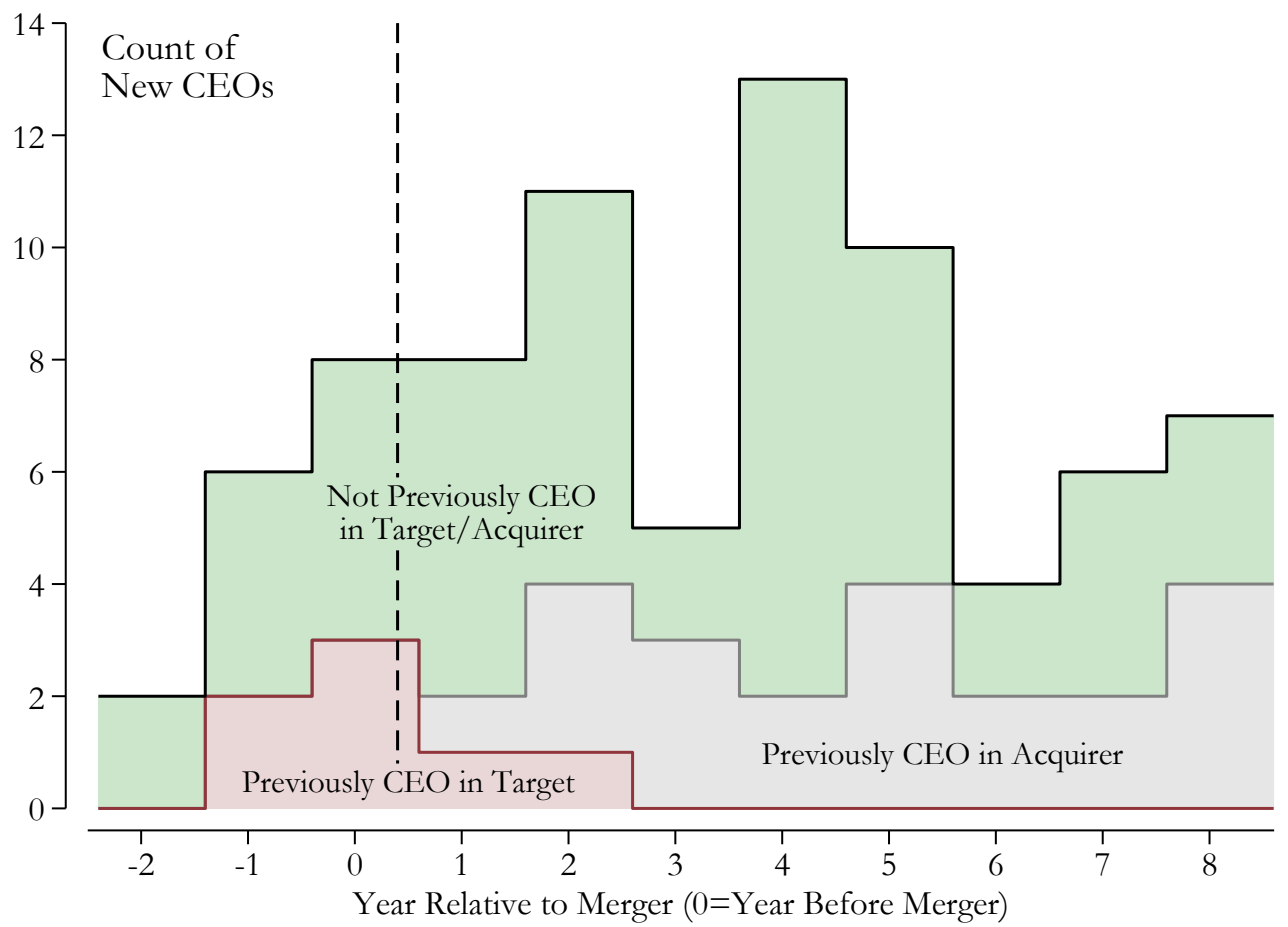

Notes: This figure shows the number of new CEOs in a balanced panel of $N=36$ target hospitals, broken out by origin into those who were previously CEOs in the target chain, those previously CEOs in the acquiring chain, those who were not previously CEOs in either chain. See text for more details. The vertical dashed line depicts the time immediately before the merger. 
Appendix To:

\section{The Anatomy of a Hospital System Merger: The Patient Did Not Respond Well to Treatment}

For Online Publication 


\section{A. Measuring Physician Flows}

We track physician entry and exit across hospitals using Medicare claims data. First, we identify hospital claims using 100\% data on inpatient stays and emergency department visits in each year. Second, we use the claims to construct a panel of physicians linked to hospital workplace(s). To identify hospitals, we use the hospital provider number on each claim. To identify physicians, we use the attending physician identifier on each claim.

The physician identifier available in the claims transitions during the 2006-2008 period from the Unique Physician Identification Number (UPIN) to the National Provider Identifier (NPI). UPINs are reported on the vast majority of claims through 2007 and NPIs are reported on nearly all claims beginning in 2008. We thus identify physicians using the UPIN through 2007 and the NPI starting in 2008. Since the flow measures for year $t$ rely on data in years $t$ and $t-1$, the change in identifiers leaves us unable to measure flows for the year 2008, and we omit this year from our analysis. To further omit cases where the identifier was not a physician, we limit the data to individual provider UPINs (using the first character of the identifier) and NPIs (using the provider type code in the NPPES, the NPI directory).

As a final step, we aggregate the claims data to a construct a physician-hospital pair panel for all years excluding 2007. For each physician-hospital pair in each year, we sum the charges on the claims. The result in a panel of physicians matched to the hospitals in which they worked in each year along with information about charges accrued for their patients treated in the hospital inpatient and emergency department setting.

Using the panel, we define the following hospital entry, exit, and churn rates:

$$
\begin{gathered}
\text { entry }_{h, t}=\frac{\sum_{p \in E_{h, t}} \operatorname{charge}_{p, h, t}}{\operatorname{AVG}\left(\text { charge }_{h, t-1}, \text { charge }_{h, t}\right)}, \text { exit }_{h, t}=\frac{\sum_{p \in X_{h, t}} \operatorname{charge}_{p, h, t-1}}{\operatorname{AVG}\left(\text { charge }_{h, t-1}, \text { charge }_{h, t}\right)} \\
\text { and } \text { churn }_{h, t}=\text { entry }_{h, t}+\text { exit }_{h, t}
\end{gathered}
$$


where $p$ indexes physicians, $h$ indexes hospitals, $t$ indexes years, $\operatorname{charg}_{p, h, t}$ is the total charges for all patients treated by the physician-hospital pair in that year, $\operatorname{charg} e_{h, t}$ is the total charges for all patients treated at that hospital in that year, $E_{h, t}$ is the hospital's entering physicians (they have charges at the hospital in $t$ but not $t-1$ ), and $X_{h, t}$ is the hospital's exiting physicians (they have charges at the hospital in $t-1$ but not $t)$. 


\section{B. Measuring Management Practices}

We surveyed hospitals using the World Management Survey instrument, which aims to measure the adoption of basic managerial practices across organizations and it has been used across organizations in manufacturing, health care, and education. The evaluation tool for health care scores a set of 20 basic management practices from one ("worst practice") to five ("best practice") in four broad areas. The operations section asks managers about the adoption of basic lean management practices; the monitoring section asks managers about their collection and use of information to monitor and improve the health care delivery process; the targets section asks about the design, integration, and realism of clinical and financial targets (separately); and the buman resource management section asks about nonmanagerial and managerial bonus, promotion, and reassignment/dismissal practices. ${ }^{1}$

For the purposes of this study, we deployed both the standard WMS instrument—which is typically directed only at clinical managers (i.e. Chief Medical Officers, Chief Nursing Officers, Chiefs of Surgery, Directors of Surgery) — and a shortened and modified version of the survey for non-clinical managers (CEOs, COOs, and CFOs). The acquirer provided a list of hospitals they deemed suitable for the study (primarily to exclude hospitals likely to be divested during the interview year) and contact information for managerial positions eligible for the survey. The survey was announced in internal town hall meetings and through email communications. These clarified that the interviews were entirely voluntary and that data would be shared with the acquirer only in aggregate form and on the condition that participants' anonymity could be protected.

The sampling frame consisted of 38 hospitals deemed by the acquirer to be suitable for the study (primarily to exclude hospitals likely to be divested during the interview year). ${ }^{2}$ We hired and

\footnotetext{
1 The survey instrument is available as an online attachment to this manuscript. A review of the instrument is available at https://worldmanagementsurvey.org/survey-data/methodology/

2 The sampling frame included 38 hospitals in 2015, of which 11 were part of the acquirer chain prior to the acquisition, 18 were part of the target chain, and 9 were acquired in later years. The data was collected and saved in a password-
} 
managed a team of interviewers to conduct the survey through in-depth phone interviews, using the standard WMS methodological approach to gather unbiased, high-quality information (Bloom et al 2020). We were able to conduct interviews at 34 of the 38 hospitals selected, interviewing 70 clinical managers (Chief Medical Officers, Chief Nursing Officers, Chiefs of Surgery, Directors of Surgery) at these facilities. To maintain comparability with the rest of the WMS data, we focus here on the interviews conducted with clinical managers. We also omit hospitals acquired by the chain after the focal merger of this study. We end up with a final sample of 49 interviews conducted across 23 hospitals. When multiple interviews per hospital were available, we average them to obtain a single hospital management score.

protected server inaccessible to the acquirer, and the survey results were shared with the acquirer only in the form of hospital averages, and only if the within-hospital sample was large enough to avoid disclosure of individual responses. 


\section{Constructing the Hospital Price Index}

To develop a price index for non-Medicare hospital payments, we draw on Dafny (2009), which notes an approach that relies on hospital cost report (HCRIS) data. We use the same data to construct our measure combined with public CMS data on hospital case-mix indexes (CMIs) in Medicare. Following Dafny (2009) and Garmon (2017), we define the price index as:

$$
\frac{\text { Discounted charges }- \text { Medicare primary payer amount }- \text { Medicare total amount payable }}{\text { CMI * (Total discharges }- \text { Medicare discharges }) * 1000},
$$

where Discounted charges is:

(Inpatient routine service charges + Intensive care charges + Inpatient ancillary charges)

$$
* \frac{\text { Net patient revenue }}{\text { Total patient charges }} \text {. }
$$




\section{Appendix Figures}

Figure A1: Stock Market Reaction to Acquisition Announcement

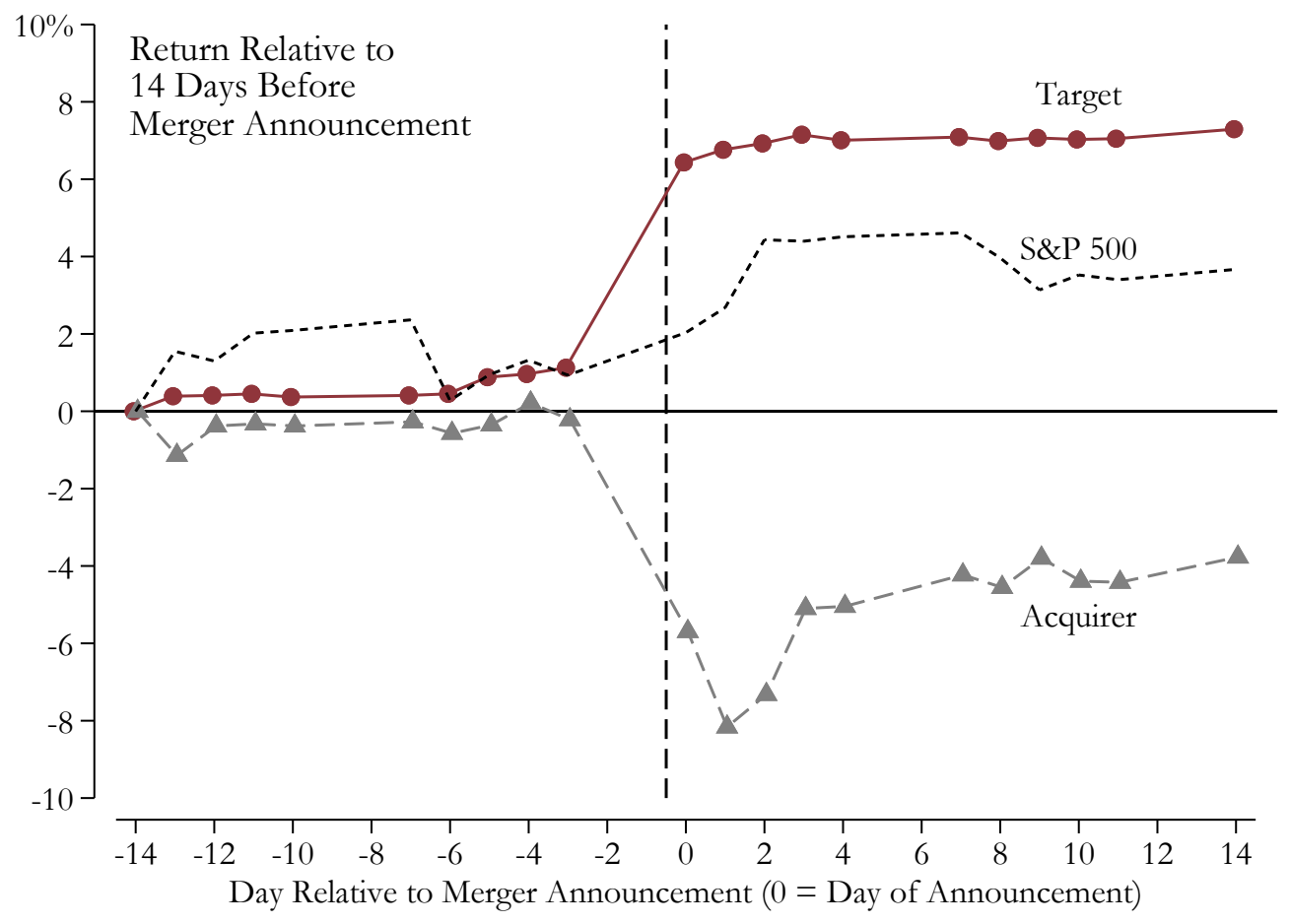

Notes: This figure depicts the evolution of stock returns for the acquirer and target firms from two weeks prior to the merger announcement to two weeks after it.

Returns for the S\&P 500 are shown as a point of comparison. Returns are relative to prices two weeks prior to the announcement. The vertical dashed line depicts the time immediately before to the merger announcement. 
Figure A2 : Additional Event Studies of Merger Effects on Hospital Inputs

A. Physician Entry Rate
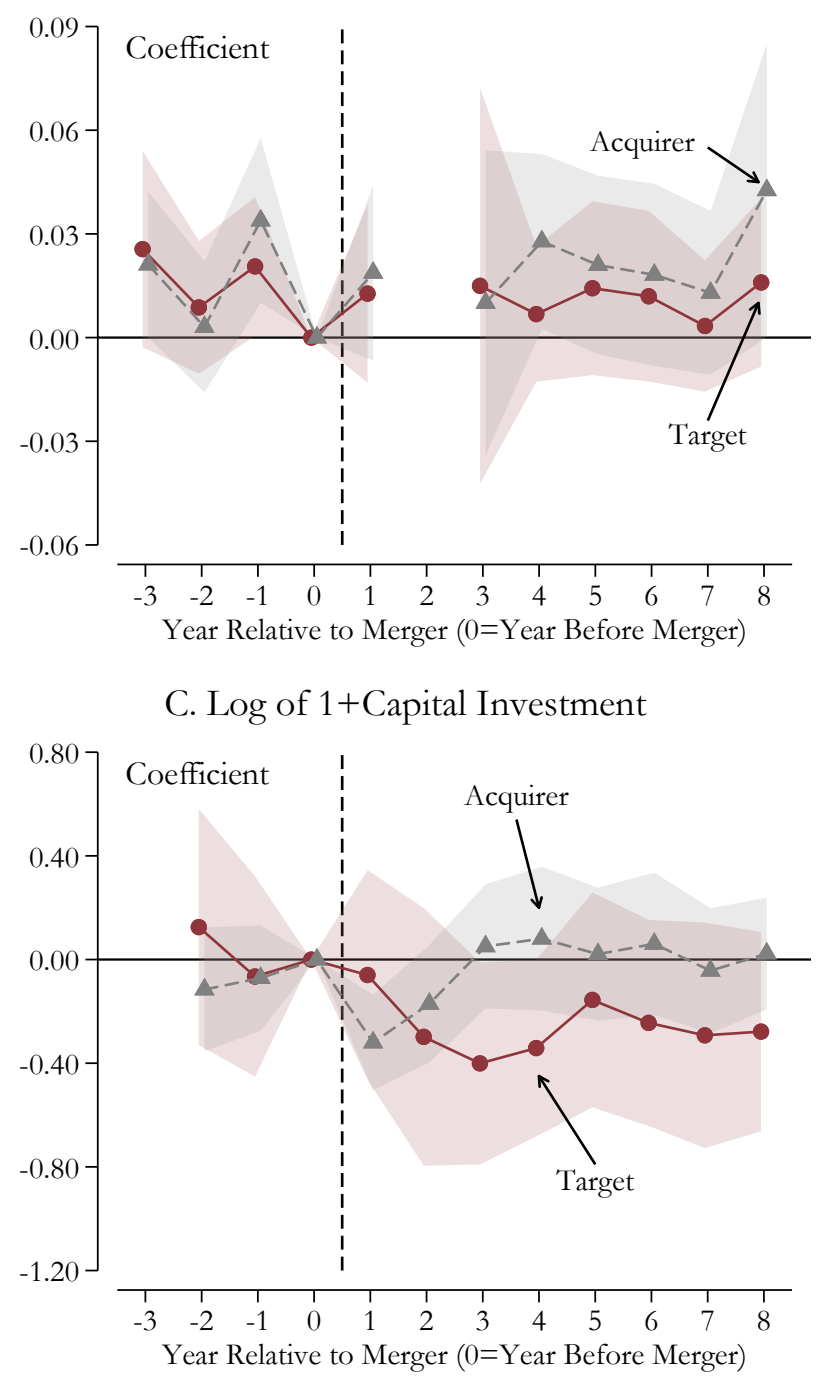

B. Log of Full-Time Employment

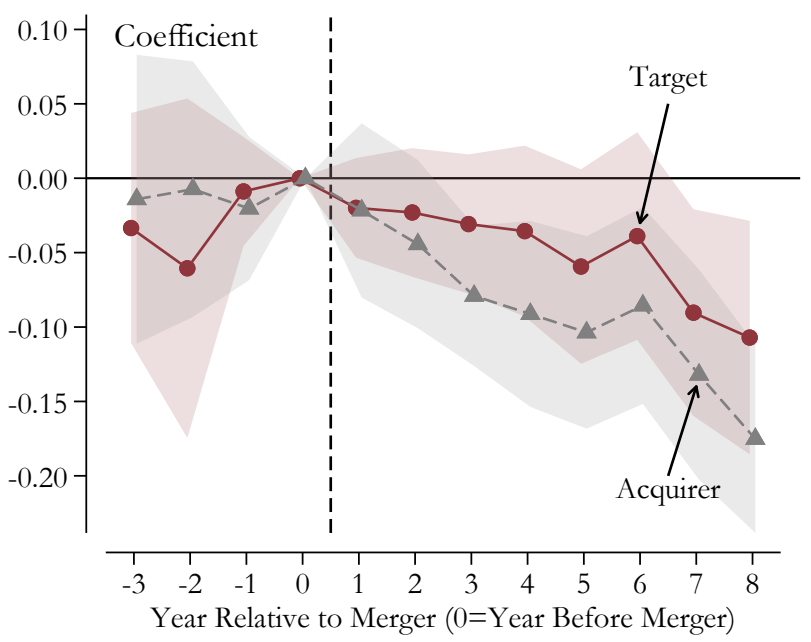

Notes: This figure shows additional event study estimates of merger effects on various measures of hospital inputs. The main event studies are presented in Figure 1 in the main text. Each panel estimates an event study version of equation (1) in which the outcome is the physician entry rate (Panel A), the logarithm of full-time employment (FTE) (Panel B), or the logarithm of $1+$ capital investment (Panel C). In Panel A, we omit the year after the merger because physician flows are not observed in this year due to a physician identifier transition. In Panel C, we add unity to capital investment before taking the logarithm to accommodate hospitals with no investment in a year; capital investment is also winsorized at 5\% on each side in each year. See text for details.

We normalize the event study to the year before the merger. Shading represents $95 \%$ confidence intervals derived from robust standard errors clustered at the hospital level. The vertical dashed line depicts the time immediately before the merger. 
Figure A3 : CEO Turnover Rates

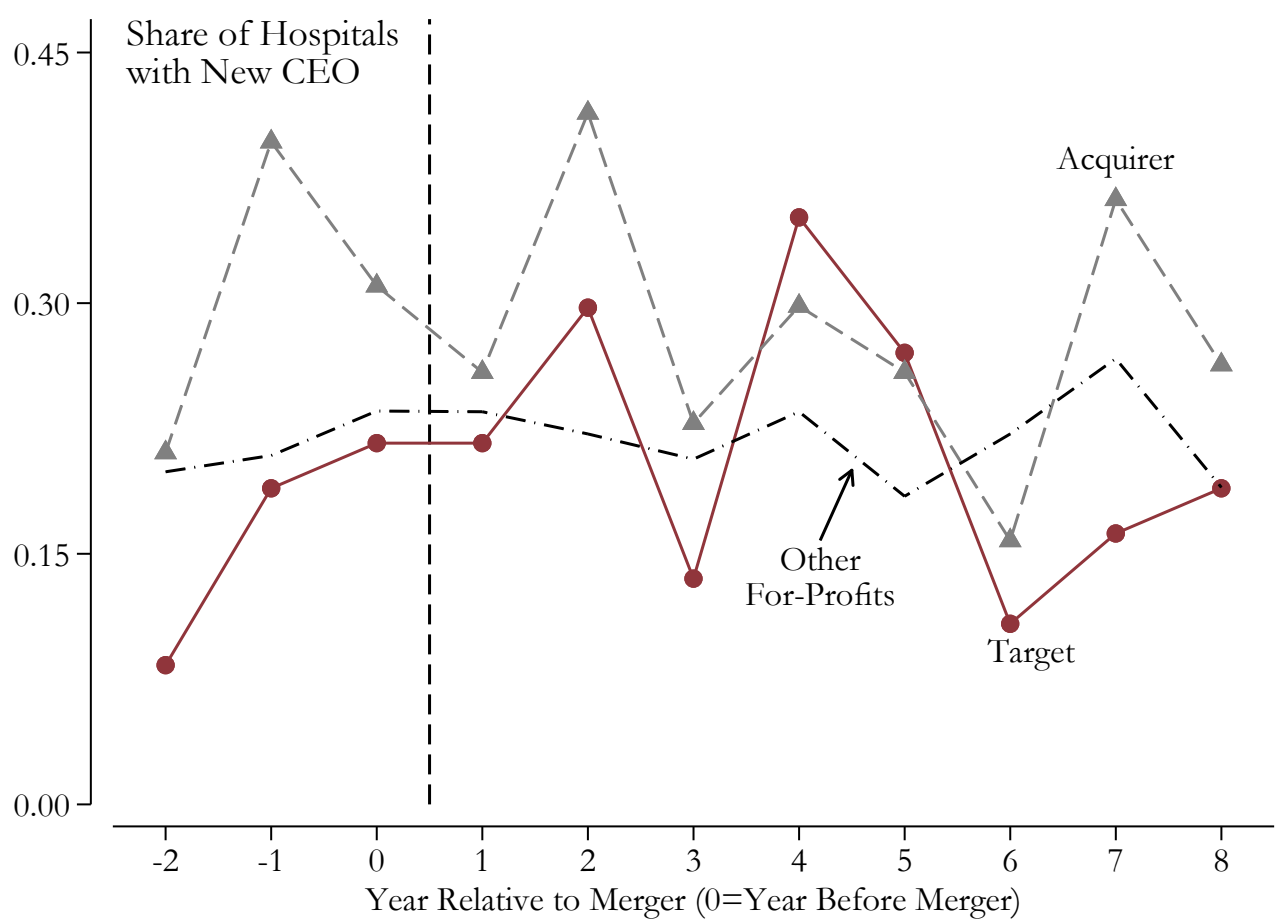

Notes: This figure shows the rate of CEO turnover at acquirer, target, and other forprofit hospitals. Turnover is defined as the share of hospitals in the group with a new $\mathrm{CEO}$ in that year. The vertical dashed line depicts the time immediately before the merger. 


\section{Appendix Tables}

Table A1: Robustness of Merger Effect Estimates to Uniform Sample

\begin{tabular}{lccccc}
\hline & $\begin{array}{c}(1) \\
\text { Post } \times \\
\text { Acquirer }\end{array}$ & $\begin{array}{c}(2) \\
\text { Std } \\
\text { Error }\end{array}$ & $\begin{array}{c}(3) \\
\text { Post } \times \\
\text { Target }\end{array}$ & $\begin{array}{c}\text { Std } \\
\text { Error }\end{array}$ & N \\
\hline A. Inputs & & & & & \\
(1) No. of discordant EMR vendors & $-1.307^{* * *}$ & $(0.166)$ & $-2.142^{* * *}$ & $(0.261)$ & 3,305 \\
(2) Physician entry rate & -0.001 & $(0.007)$ & -0.004 & $(0.007)$ & 3,305 \\
(3) Physician exit rate & -0.002 & $(0.006)$ & 0.006 & $(0.005)$ & 3,305 \\
(4) Physician churn rate & -0.002 & $(0.010)$ & 0.002 & $(0.009)$ & 3,305 \\
(5) Log of FTE & $-0.064^{* *}$ & $(0.029)$ & 0.001 & $(0.045)$ & 3,305 \\
(6) Log of 1+capital investment & -0.000 & $(0.093)$ & $-0.424^{* * *}$ & $(0.140)$ & 3,305 \\
B. Financial Outcomes & & & & & \\
(7) Log of costs per inpatient & $0.101^{* * *}$ & $(0.024)$ & 0.015 & $(0.032)$ & 3,305 \\
(8) Log of price index & 0.127 & $(0.141)$ & 0.106 & $(0.107)$ & 3,305 \\
(9) Log of revenue per inpatient & 0.042 & $(0.028)$ & 0.023 & $(0.029)$ & 3,305 \\
(10) Profit margin & $-0.037^{* * *}$ & $(0.013)$ & 0.008 & $(0.012)$ & 3,305 \\
\hline
\end{tabular}

Notes: This table displays the robustness of the findings on inputs and financials to restricting to the sample of observations with complete data on all such outcomes. See notes to Table 2 for more details on the measures and specifications.

Robust standard errors clustered at the hospital level in parentheses. Effects significant at 10\% (*), $5 \%(* *)$, and 1\%(***). EMR: electronic medical record. 
Table A2: Robustness of Merger Effect Estimates to Area-Year Controls

\begin{tabular}{lccccc}
\hline & $\begin{array}{c}(1) \\
\text { Post } \times \\
\text { Acquirer }\end{array}$ & $\begin{array}{c}\text { Std } \\
\text { Error }\end{array}$ & $\begin{array}{c}(3) \\
\text { Post } \times \\
\text { Target }\end{array}$ & $\begin{array}{c}\text { Std } \\
\text { Error }\end{array}$ & N \\
\hline A. Inputs & & & & & \\
(1) No. of discordant EMR vendors & $-1.408^{* * *}$ & $(0.266)$ & $-3.226^{* * *}$ & $(0.649)$ & 2,853 \\
(2) Physician entry rate & 0.004 & $(0.013)$ & 0.002 & $(0.010)$ & 3,802 \\
(3) Physician exit rate & -0.007 & $(0.007)$ & 0.015 & $(0.009)$ & 3,802 \\
(4) Physician churn rate & -0.003 & $(0.014)$ & 0.017 & $(0.017)$ & 3,802 \\
(5) Log of FTE & -0.053 & $(0.039)$ & -0.059 & $(0.067)$ & 4,387 \\
(6) Log of 1+capital investment & $0.224^{*}$ & $(0.115)$ & -0.209 & $(0.195)$ & 4,055 \\
B. Financial Outcomes & & & & & \\
(7) Log of costs per inpatient & $0.059^{* *}$ & $(0.029)$ & 0.038 & $(0.052)$ & 4,380 \\
(8) Log of price index & $0.539^{* * *}$ & $(0.200)$ & 0.059 & $(0.195)$ & 3,995 \\
(9) Log of revenue per inpatient & $0.066^{*}$ & $(0.037)$ & 0.083 & $(0.063)$ & 4,380 \\
(10) Profit margin & -0.005 & $(0.012)$ & 0.006 & $(0.019)$ & 4,363 \\
C. Clinical Outcomes & & & & & \\
(11) Survival & $-0.009^{*}$ & $(0.005)$ & -0.003 & $(0.007)$ & 4,582 \\
(12) Readmission & -0.008 & $(0.005)$ & 0.004 & $(0.005)$ & 4,582 \\
\hline
\end{tabular}

Notes: This table displays the robustness of the findings on inputs, financials, and clinical outcomes reported in Table 2 to the inclusion of area-year fixed effects (Panels A and B) and area-cohort-year fixed effects (Panel C). Areas are defined as Hospital Referral Regions (HRRs). Sample sizes differ from Table 2 because they do not count singleton observations (e.g. area-years containing only one hospital). See notes to Table 2 for more details on the measures and specifications.

Robust standard errors clustered at the hospital level in parentheses. Effects significant at 10\% $\left(^{*}\right)$, $5 \%(* *)$, and 1\%(***). EMR: electronic medical record. 
Table A3: Origin of New CEOs before and after Acquisition

\begin{tabular}{lcccccc}
\hline & & \multicolumn{2}{c}{ Target } & & \multicolumn{2}{c}{ Acquirer } \\
\cline { 1 - 1 } \cline { 6 - 7 } Source of CEO & & Before & After & & Before & After \\
Target & & 0.31 & 0.03 & & 0.00 & 0.02 \\
Acquirer & & 0.00 & 0.28 & & 0.19 & 0.34 \\
External system or hospital & & 0.25 & 0.07 & & 0.40 & 0.15 \\
Not previously hospital CEO & & 0.44 & 0.62 & & 0.40 & 0.49 \\
\hline
\end{tabular}

Notes: This table displays the source of new CEOs arriving at target and acquirer hospitals before (2004-2006) and after (2007-2010) the acquisition. 
Table A4: Selected Granular Cost Outcomes

\begin{tabular}{|c|c|c|c|c|c|c|c|c|}
\hline $\begin{array}{l}\text { Outcome: Log } \\
\text { of } 1+\text { Costs per } \\
\text { Inpatient }\end{array}$ & Total & $\begin{array}{c}(2) \\
\text { General } \\
\text { Service } \\
\end{array}$ & $\begin{array}{c}(3) \\
\text { Central } \\
\text { Services/ } \\
\text { Supply } \\
\end{array}$ & $\begin{array}{c}\text { (4) } \\
\text { Medical } \\
\text { Records }\end{array}$ & $\begin{array}{c}\text { (5) } \\
\text { Nursing } \\
\text { Admin } \\
\end{array}$ & Pharmacy & $\begin{array}{c}\text { (7) } \\
\text { Capital } \\
\text { Equipment } \\
\end{array}$ & Laundry \\
\hline Post* Acquirer & $\begin{array}{c}0.095^{* * *} \\
(0.020)\end{array}$ & $\begin{array}{c}0.213^{* * *} \\
(0.028)\end{array}$ & $\begin{array}{c}0.152^{* * *} \\
(0.022)\end{array}$ & $\begin{array}{c}0.020^{* * *} \\
(0.003)\end{array}$ & $\begin{array}{c}0.026^{* * *} \\
(0.004)\end{array}$ & $\begin{array}{c}0.080^{* * *} \\
(0.011)\end{array}$ & $\begin{array}{c}0.054 * * * \\
(0.011)\end{array}$ & $\begin{array}{c}0.004 * * \\
(0.002)\end{array}$ \\
\hline Post $*$ Target & $\begin{array}{l}-0.003 \\
(0.028)\end{array}$ & $\begin{array}{c}0.331^{* * *} \\
(0.047)\end{array}$ & $\begin{array}{c}0.355^{* * *} \\
(0.026)\end{array}$ & $\begin{array}{c}0.012^{* * *} \\
(0.004)\end{array}$ & $\begin{array}{c}0.058^{* * *} \\
(0.006)\end{array}$ & $\begin{array}{c}0.096^{* * *} \\
(0.018)\end{array}$ & $\begin{array}{c}0.189 * * * \\
(0.014)\end{array}$ & $\begin{array}{l}0.004^{*} \\
(0.002)\end{array}$ \\
\hline Observations & 5,257 & 5,059 & 5,059 & 5,059 & 5,059 & 5,059 & 5,059 & 5,059 \\
\hline
\end{tabular}

Notes: This table displays the results of estimating equation 1 with hospital cost measures as the outcome. Each column presents a different cost measure; only cost measures with statistically significant and positive effects at the $5 \%$ level for the acquirer are shown. The outcome is defined as the logarithm of $1+$ the cost measure per inpatient discharge (specifically, before adding 1 and logging, we divide cost by the measure of adjusted inpatient discharges laid out in Schmitt, 2017). Each observation is a hospital-year. All regressions include hospital and year fixed effects. Column 1 studies logged total costs per inpatient (repeated from Table 2; unlike the other columns we do not add unity before logging to match estimates in the main text and because this outcome is rarely zero). Column 2 studies logged general service costs, a subset of total hospital costs. Columns 3-8 study varying subsets of general services costs. These measures are winsorized at 5\% on each side in each year.

Robust standard errors clustered at the hospital level in parentheses. Effects significant at 10\% (*), 5\% (**), and 1\% (***). 